\title{
Caracterização das queimadas acidentais em campo, no Município de Santa Maria-RS
}

\author{
Characterization of accidental field burns in the county of Santa Maria-RS, Brazil
}

\author{
Luciane Flores Jacobi ${ }^{I}$ Alessandro Dal’Col LúcioII Lindolfo Storck ${ }^{\text {II }}$ Sidinei José Lopes ${ }^{\text {II }}$ \\ Alberto Cargnelutti Filho'I
}

\section{- NOTA-}

\section{RESUMO}

Neste trabalho o objetivo foi realizar um estudo de queimadas acidentais em campo, foi para identificar, caracterizar e localizar lugares de maior ocorrência dessas na cidade de Santa Maria-RS, com intuito de auxiliar no planejamento e controle de incêndios. A variável de interesse foi o número de chamadas recebidas, por dia, pelo Corpo de Bombeiros de Santa Maria, no período de $1^{\text {o }}$ de janeiro de 1993 a 31 de dezembro de 2004. Verificou-se que, em média, o Corpo de Bombeiros recebeu 1,81 chamadas diárias; que antes da ocorrência de uma chamada não chovia, em média, há quatro dias; a grande maioria ocorreu no período da tarde $e$ às margens das rodovias que circundam a cidade, principalmente, na $R S 287$, rodovia com margens pouco habitadas. $O$ mês em que ocorreu o maior número de chamadas ao Corpo de Bombeiros foi agosto, sendo o ano de 1999, o que acumulou maior ocorrência de queimadas. Além disso, o número de chamadas distribui-se uniformemente nos dias da semana. As margens das rodovias e os bairros Distrito Industrial, Medianeira, Itararé, Tomazzetti e Parque Pinheiro Machado foram as áreas com maiores chances de ocorrência de queimadas.

Palavras-chave: manejo agropastoril, estatística descritiva, fogo, queimadas

\section{ABSTRACT}

The objetive of this research was to conduct a study on accidental field burns in the county of Santa Maria-RS, Brazil to identify and characterize sites where they most frequently occur with the objective of helping in the planning and controlling of those burns. The variable of interest was the number of daily calls received by the Santa Maria Fire Department, from January $1^{\text {st }} 1993$ to December $31^{\text {st }} 2004$. It was observed that the Fire Department received on average 1.81 daily calls; that the calls were followed by a dry period of four days, on average; and most calls occurred during the afternoon and alongside the almost unhabited RS 287 highway. The month with the highest number of calls was August, and the year 1999 presented the highest occurrence number of field burns. Finally, the number of calls was equally distributed along the weekdays. The margins of the highways and the following city districts: Distrito Industrial, Medianeira, Itararé, Tomazzetti and Parque Pinheiro Machado presented the highest chances of burnings occurrence.

Key words: agriculture and cattle raising management, descriptive statistics, fire, burns.

Há séculos o fogo acompanha o homem e, através dele, registra-se a história da humanidade, sendo um marco no processo evolutivo da humanidade. Com seu domínio, alcançaram-se novos espaços, alteraram-se ecossistemas, e sofreram suas conseqüências, decorrentes de suas próprias atividades. A quase totalidade das queimadas é causada pelo homem, por razões muito variadas, como limpeza de pastos, preparo de plantios, desmatamentos, colheita manual de cana-de-açúcar, vandalismo, balões de festas juninas, disputas fundiárias, protestos sociais, etc.. Com mais de 300.000 focos de calor e nuvens de fumaça

'Departamento de Estatística, Centro de Ciências Naturais e Exatas (CCNE), Universidade Federal de Santa Maria (UFSM), 97105-

900, Santa Maria, RS, Brasil. E-mail: 1fjacobi@smail.ufsm.br. Autor para correspondência.

IIDepartamento de Fitotecnia, Centro de Ciências Rurais (CCR), UFSM, Santa Maria, Brasil. 
cobrindo milhões de $\mathrm{km}^{2}$ que são detectadas, anualmente, por satélites, o Brasil ocupa lugar de destaque como um grande poluidor e devastador (CPETC, 2007).

Em áreas de campo, as queimadas constituem uma das tradições mais arraigadas na Região Sul do Brasil seja para limpeza de terrenos a serem cultivados seja para preparação de pastagens. Em campos nativos, a vegetação que renasce aparenta mais força e melhor aparência, só que, ao longo dos anos, as queimadas provocam a degradação gradativa do solo e das plantas. A degradação das pastagens tem afetado diretamente a sustentabilidade da pecuária nacional, além de diminuir o valor das terras e atrasar a idade de abate dos animais. Persistindo o processo de degradação, com certeza, haverá prejuízos irrecuperáveis para os recursos naturais (PERON \& EVANGELISTA, 2004).

Dessa forma, no presente trabalho, o objetivo foicrealizar um estudo de queimadas acidentais em campo para caracterizar e localizar locais (bairros) de maior ocorrência dessas na cidade de Santa Maria - RS, com intuito de auxiliar no planejamento e no controle de incêndios. $\mathrm{O}$ estudo baseou-se no número de chamadas diárias recebidas pelo Corpo de Bombeiros de Santa Maria, no período de 1o de janeiro de 1993 a 31 de dezembro de 2004, e no local de ocorrência da queimada.

Foram identificados os locais com maior número de ocorrências, sendo esses dados agrupados por bairro, conforme a divisão vigente no Município de Santa Maria - RS, em 2005. Em seguida, foram obtidos os quartis da variável freqüência de queimadas por local de ocorrência, estabelecendo-se que os bairros (com freqüência de queimadas) abaixo do $1^{\circ}$ quartil estavam na classe de baixa chance de ocorrência de queimadas acidentais, os bairros entre o $1^{\circ}$ e o $3^{\circ}$ quartil, numa classe média e os bairros acima do $3^{\circ}$ quartil estavam em uma classe com alta chance de ocorrência de queimadas em campo.

No período de janeiro de 1993 a dezembro de 2004, o Corpo de Bombeiros recebeu um total de 1765 chamadas, distribuídas em 973 dias de um total de 4383 dias catalogados. Esse número de chamadas não está de acordo com o número de focos de calor observados pelos satélites que fazem essa investigação no país, pois para o mesmo período, os satélites registraram, em Santa Maria, apenas 13 focos de calor.

Verificou-se que, em 77,80\% dos dias do período avaliado, o Corpo de Bombeiros não recebeu chamadas para combater queimadas em campo, no Município. Na tabela 1 estão apresentadas as principais medidas descritivas dos fatores meteorológicos, para os dias em que o Corpo de Bombeiros recebeu chamadas para combater fogo, em campo, no referido Município. Pode-se observar que o Corpo de Bombeiros, no período avaliado, não recebeu muitas chamadas diárias para combater queimadas, pois $25 \%$ delas foram superiores a dois ( $3^{\circ}$ quartil), chegando ao

Tabela 1 - Medidas descritivas da umidade relativa às nove horas $\left(\mathrm{UR}_{9}\right)$, às quinze horas $\left(\mathrm{UR}_{15}\right)$ e às vinte e uma horas $\left(\mathrm{UR}_{21}\right)$, insolação $(\mathrm{Ia})$, precipitação total (prtol), velocidade do vento em $\mathrm{m} / \mathrm{s}$ (velvent) e número de dias sem precipitação pluviométrica (NDPP), para os dias que ocorreram e não ocorreram chamadas ao Corpo de Bombeiros, no período de janeiro de 2003 a dezembro de 2004 , em Santa Maria - RS

\begin{tabular}{|c|c|c|c|c|c|c|c|c|c|c|}
\hline Variáveis & $\mathrm{N}$ & Média & Mediana & Moda & $\begin{array}{c}\text { Freqüência } \\
\text { Modal }\end{array}$ & Mínimo & Máximo & $1^{\circ}$ Quartil & $3^{\circ}$ Quartil & $\begin{array}{l}\text { Desvio } \\
\text { padrão }\end{array}$ \\
\hline queimadas & 973 & 1,81 & 1,00 & 1,00 & 607 & 1,00 & 11,00 & 1,00 & 2,00 & 1,48 \\
\hline UR9 & 973 & 77,17 & 79,00 & 98,00 & 55 & 30,00 & 100,00 & 68,00 & 90,00 & 15,31 \\
\hline UR15 & 973 & 52,51 & 51,00 & 48,00 & 43 & 19,00 & 98,00 & 44,00 & 60,00 & 13,53 \\
\hline UR21 & 973 & 76,10 & 78,00 & 81,00 & 38 & 35,00 & 99,00 & 68,00 & 86,00 & 13,27 \\
\hline Ia & 973 & 8,05 & 8,90 & 0,00 & 33 & 0,00 & 12,60 & 6,40 & 10,30 & 3,23 \\
\hline prtol & 973 & 2,97 & 0,00 & 0,00 & 771 & 0,00 & 136,60 & 0,00 & 0,00 & 10,30 \\
\hline velvent & 973 & 70,98 & 61,80 & 54,60 & 5 & 8,00 & 783,60 & 42,50 & 88,00 & 47,23 \\
\hline \multirow[t]{2}{*}{ NDPP } & 973 & 4,39 & 4,00 & 2,00 & 133 & 0,00 & 21,00 & 2,00 & 6,00 & 3,73 \\
\hline & \multicolumn{10}{|c|}{ Para os dias em que não ocorreram chamadas ao Corpo de Bombeiros } \\
\hline ur9 & 3410 & 86,11 & 89,00 & 98,00 & 462 & 10,00 & 100,00 & 79,00 & 96,00 & 11,51 \\
\hline ur15 & 3410 & 66,30 & 64,00 & 98,00 & 114 & 17,00 & 100,00 & 54,00 & 79,00 & 16,69 \\
\hline ur21 & 3410 & 85,25 & 88,00 & 98,00 & 275 & 29,00 & 100,00 & 79,00 & 94,00 & 10,53 \\
\hline insol & 3410 & 5,44 & 5,80 & 0,00 & 613 & 0,00 & 13,30 & 1,00 & 9,00 & 4,10 \\
\hline prtol & 3410 & 5,87 & 0,00 & 0,00 & 2042 & 0,00 & 136,50 & 0,00 & 3,20 & 14,05 \\
\hline velvent & 3410 & 59,55 & 52,75 & 34,00 & 15 & 0,60 & 781,50 & 35,00 & 76,20 & 37,58 \\
\hline NDPP & 3410 & 1,89 & 1,00 & 0,00 & 1462 & 0,00 & 23,00 & 0,00 & 3,00 & 2,76 \\
\hline
\end{tabular}


máximo de 11, sendo que, dos 973 dias que ocorreram chamadas ao Corpo de Bombeiros, em 607, eles receberam apenas uma chamada para combater fogo em campo. Também em 79\% dos dias em que houve chamadas, não foi registrada precipitação pluviométrica, sendo que desses $13,7 \%$, há dois dias não chovia. Entre os dias em que ocorreram chamadas, em $60 \%$, não ocorreu precipitação, em $43 \%$, havia chovido no dia anterior e em $25 \%$ chovera mais de $3 \mathrm{~mm}$.

Nos dias em que ocorreram chamadas, a temperatura máxima, a insolação, a velocidade do vento e o número de dias sem precipitação foram, significativamente superiores, pelo teste U de MannWhitney, adotando-se um nível de significância de 5\%, e a umidade relativa das 9,15 e $21 \mathrm{~h}$ e a precipitação foram, significativamente inferiores, pelo mesmo teste e mesmo nível de significância, nos dias em que não ocorreram chamadas (Tabela 1). Verificou-se também que $70 \%$ das chamadas concentraram-se, principalmente, no período entre 13 e $20 \mathrm{~h}$, o que pode ser explicado pelo fato de que no período da manhã o campo está, freqüentemente, úmido.

Os meses de janeiro, julho, dezembro e em especial, agosto, foram os que apresentaram um maior número de chamadas (Tabela 2), de acordo com dados do INPE que observou, durante o período de junho a novembro, que grande parte do país é acometido por queimadas, que se estendem praticamente por todas as regiões, com maior ou menor intensidade. Além disso, conforme FERNANDES et al. (1998), os meses de janeiro a abril também possuem alta concentração desse fato, que ocorrem nos períodos de estiagem do verão. Observou-se também que o número de chamadas recebidas pelo Corpo de Bombeiros para combate a queimadas oscila muito de ano para ano, sendo que suas maiores ocorrências foram nos anos de 1999 e 2004. Cruzando o número de chamadas recebidas pelo Corpo de Bombeiros com o dia da semana, verificou-se, pelo teste do Qui-quadrado $\left(\chi_{\mathrm{c}}^{2}=10,71 ; \mathrm{P}<0,999\right)$ que essas se distribuem uniformemente, durante os dias da semana.

Observa-se na tabela 3 que os locais com maior ocorrência de queimadas são as margens das rodovias RS 287, BR158 e BR392 (35,18\%) que contornam Santa Maria, principalmente, a RS 287 (17,17\%), que passa pelos bairros Camobi, Urlândia, Santa Marta e Tancredo Neves. Além das rodovias, em quarto lugar, aparece o Distrito Industrial, que fica afastado do centro da cidade e, portanto, circundado por campos. A Região Oeste do Município foi a mais afetada pelas queimadas. Isso ocorre por ser uma região que está em fase de crescimento, não muito populosa, com muito campo ou terrenos baldios que são limpos com a utilização do fogo. A maior responsável pelas queimadas nas margens das rodovias, segundo BERNA (2002) e TEBE (2004), são as pontas de cigarros jogadas pelos motoristas. Já no meio urbano, o que contribui para o aumento do número de incêndios, é a falta ou baixa freqüência da coleta de lixo, fazendo com que os moradores, para se livrarem do lixo, ateiem-lhe fogo, o qual, facilmente, se alastra pelo capim seco.

A região onde se localiza o Distrito Industrial do Município é contornada por duas rodovias, agravando o problema das queimadas, sendo que para um maior controle e atendimento às chamadas foi instalado (em agosto de 1994), nessa região, um posto do Corpo de Bombeiros. Nos bairros Medianeira e Tomazetti, há o entroncamento de duas rodovias, a BR 158 e a BR 392, que é a saída para os caminhões que

Tabela 2 - Evolução do número de chamadas recebidas pelo Corpo de Bombeiros de Santa Maria - RS no período de 1993 a 2004 , em Santa Maria - RS.

\begin{tabular}{|c|c|c|c|c|c|c|c|c|c|c|c|c|c|}
\hline Meses & 1993 & 1994 & 1995 & 1996 & 1997 & 1998 & 1999 & 2000 & 2001 & 2002 & 2003 & 2004 & Total \\
\hline Janei ro & 6 & 22 & 8 & 9 & 18 & 6 & 29 & 45 & 4 & 59 & 9 & 20 & 235 \\
\hline Fevereiro & 5 & 3 & 7 & 1 & 0 & 4 & 8 & 7 & 3 & 16 & 7 & 30 & 91 \\
\hline Março & 7 & 7 & 9 & 2 & 10 & 3 & 47 & 4 & 5 & 3 & 2 & 43 & 142 \\
\hline Abril & 2 & 6 & 12 & 2 & 15 & 11 & 6 & 6 & 4 & 7 & 8 & 9 & 88 \\
\hline Maio & 1 & 4 & 5 & 6 & 12 & 4 & 6 & 3 & 9 & 6 & 14 & 2 & 72 \\
\hline Junho & 1 & 1 & 10 & 16 & 3 & 4 & 1 & 14 & 12 & 17 & 1 & 9 & 89 \\
\hline Julho & 3 & 24 & 27 & 26 & 23 & 3 & 9 & 10 & 15 & 7 & 22 & 27 & 196 \\
\hline Agosto & 46 & 25 & 38 & 38 & 18 & 8 & 41 & 44 & 35 & 18 & 56 & 4 & 371 \\
\hline Setembro & 9 & 6 & 3 & 16 & 8 & 5 & 7 & 25 & 0 & 11 & 26 & 16 & 132 \\
\hline Outubro & 4 & 0 & 6 & 0 & 1 & 4 & 4 & 1 & 5 & 1 & 9 & 8 & 43 \\
\hline Novembro & 8 & 9 & 27 & 8 & 4 & 8 & 14 & 4 & 11 & 3 & 1 & 18 & 115 \\
\hline Dezembro & 9 & 11 & 36 & 7 & 9 & 17 & 45 & 3 & 17 & 7 & 3 & 27 & 191 \\
\hline Total & 101 & 118 & 188 & 131 & 121 & 77 & 217 & 166 & 120 & 155 & 158 & 213 & 1765 \\
\hline
\end{tabular}

Ciência Rural, v.39, n.3, mai-jun, 2009. 
Tabela 3 - Locais e respectivos números de ocorrências de queimadas em campo, em Santa Maria - RS, de janeiro de 1993 a dezembro de 2004.

\begin{tabular}{|c|c|c|}
\hline Chances de ocorrência de queimadas & Local/Bairro & Número de queimadas \\
\hline \multirow{9}{*}{ Alta } & RS287 & 303 \\
\hline & BR 158 & 187 \\
\hline & BR392 & 131 \\
\hline & Distrito Industrial & 98 \\
\hline & Medianeira & 80 \\
\hline & BR509 & 77 \\
\hline & Itararé & 70 \\
\hline & Tomazzet ti & 65 \\
\hline & Parque Pinheiro Machado & 57 \\
\hline \multirow{18}{*}{ Média } & Caturrita & 51 \\
\hline & São José & 49 \\
\hline & Não localizada & 44 \\
\hline & UFSM & 43 \\
\hline & Camobi & 41 \\
\hline & Nossa Senhora de Lourdes & 40 \\
\hline & ITAARA & 34 \\
\hline & Passo das Tropas & 30 \\
\hline & Presidente João Goulart & 29 \\
\hline & Distritos & 29 \\
\hline & Perpétuo Socorro & 28 \\
\hline & Chácara das Flores & 26 \\
\hline & Patronato & 26 \\
\hline & Tancredo Neves & 25 \\
\hline & Passo D’Areia & 24 \\
\hline & Jucelino Kubitschek & 24 \\
\hline & Morro do Cerrito & 20 \\
\hline & Centro & 19 \\
\hline \multirow{9}{*}{ Baixa } & Boi Morto & 15 \\
\hline & Nossa Senhora das Dores & 15 \\
\hline & Cerrito & 15 \\
\hline & Urlândia & 15 \\
\hline & Pé de Plátano & 13 \\
\hline & Rosário & 12 \\
\hline & KM 3 & 9 \\
\hline & Novo Horizonte & 5 \\
\hline & SC Dores & 3 \\
\hline
\end{tabular}

se destinam ao Porto de Rio Grande, caracterizando uma das mais movimentadas saídas do Município, enquanto que outra região, a do Bairro Itararé, teve grande ocorrência de chamadas que podem ser explicadas pelo fato de nesse bairro estar a maior concentração dos trilhos da rede ferroviária, encontrase a antiga estrada que ligava o município ao norte do Estado, ainda muito utilizada pelos motoristas e, ainda devido a ser margeada por morros que apresentam vegetação intensa.

Dessa forma, pode-se concluir que o número de chamadas diárias recebidas pelo Corpo de
Bombeiros para combater queimadas em campo em Santa Maria não ocorre com muita freqüência, pois apenas em vinte e cinco porcento dos dias avaliados, houve mais de duas chamadas diárias e o número de chamadas distribuiu-se, uniformemente, nos dias de semana. Em média, antes da ocorrência de uma chamada, não chovia há quatro dias, sendo que a grande maioria ocorreu no período da tarde e nas margens das rodovias que circundam a cidade, notadamente, a RS 287, rodovia com as margens pouco habitadas. O mês em que ocorreu o maior número de chamadas ao Corpo de Bombeiros foi agosto, sendo

Ciência Rural, v.39, n.3, mai-jun, 2009. 
o ano de 1999 o que acumulou maior ocorrência de queimadas.

\section{REFERÊNCIAS}

BERNA, V. Problemas ambientais - III. EngWhere - Por Dentro da Obra, n.14, dez 2002. Acesso em: 21 mai 2007. On line. Disponível em: <http://www.engwhere.com.br/revista/ obras de engenharia.htm $>$.

CPTEC Centro de previsão de tempo e estudos climáticos. Acesso em: 22 jan. 2007. On line. Disponível em: <http:// www.cptec.inpe.br/queimadas/apresentacao.htm>.

LEVINE, D.M. et al. Estatística: teoria e aplicações. Rio de Janeiro: Livros Técnicos e Científicos, 2000. 811p.
PERON, A.J.; EVANGELISTA, A.R. Degradação de pastagens em regiões de cerrado. Ciência e Agrotecnologia, Lavras, v.28, n.3, p.655-661, 2004.

TEBE - Concessionária de Rodovias. TEBE em revista. n.6, ago, 2004. Acesso em: 21 mai 2007. On line. Disponível em: $<$ http://www.tebe.com.br/fotosarquivos/arquivosrevista/ revistatebe2004agosto.pdf $>$.

FERNANDES, M. do C. et al. potencialidade de ocorrência de queimadas no maciço da Tijuca/RJ: uma abordagem utilizando geoprocessamento. In: SIMPÓSIO BRASILEIRO DE SENSORIAMENTO REMOTO, 9., 1998, Santos. Anais eletrônicos... Santos: INPE, 1998. Acesso em: 22 jan. 2007. On line. Disponível em: <http://marte.dpi. inpe.br/col/ sid.inpe.br/deise/1999/02.08.11.22/doc/7_128o.pdf $>$. 